\title{
Shifting Paradigm of Education Landscape in Time of the COVID-19 Pandemic: Revealing of a Digital Education Management Information System
}

\author{
Fahmi Ibrahim ${ }^{1,+}{ }^{\text {, Heru Susanto }}{ }^{1,2,3, *,+}$, , Parastou Khodaparast Haghi ${ }^{4}$ and Desi Setiana ${ }^{5,6}$ \\ 1 School of Business, Universiti Technologi of Brunei, Bandar Seri Begawan BE 1410, Brunei Darussalam; \\ fahmi.ibrahim@utb.edu.bn \\ 2 Research Center for Informatics, The Indonesia Institute of Sciences, Jakarta 12710, Indonesia \\ 3 Information Management, Tunghai University, Taichung 40704, Taiwan \\ 4 Faculty of Art and Architecture, University of Guilan, Rasht 4199613776, Iran; PKHaghi@gmail.com \\ 5 Ministry of Law and Human Right, Jakarta 12940, Indonesia; desi.setiana@gmail.com \\ 6 Academy of Asian Studies, University of Brunei Darussalam, Jalan Tungku Link BE1410, Brunei Darussalam \\ * Correspondence: heru.susanto@utb.edu.bn \\ $+\quad$ Main Contributor and Lead Author.
}

Received: 30 August 2020; Accepted: 12 October 2020; Published: 10 November 2020

\begin{abstract}
The COVID-19 pandemic has indirectly changed the landscape of the country's education system. Through information-based decision-making, the management of the education system seeks to increase the access to and efficiency, effectiveness, equity and quality of education through effective systems of monitoring, evaluation, budgeting and planning. From this perspective, an Integrated National Education Information System (iNEIS ${ }^{\mathrm{TM}}$ ) was developed to streamline and transform business processes and to provide an application and technology platform to comply with the National Education System that may be suitable for the COVID-19 pandemic environment. The implementation of iNEIS ${ }^{\mathrm{TM}}$ aimed to significantly improve operational efficiency and productivity and provide better services, value and "holistic education" to students. Therefore, the purpose of this study was to investigate the effectiveness of the newly implemented, integrated iNEIS ${ }^{\mathrm{TM}}$ and its implications for educational management systems that were implemented during the COVID-19 pandemic. It specifically examines the benefits and obstacles that hinder the efficiency and effectiveness of the system. The result is very interesting. These findings demonstrate that there was a lack of positive impact on end-users, such as lacking readiness to accept organizational change and uncoordinated communication and information exchange between stakeholders and end-users. This research implies that when both the stakeholder-provider and end-user understand the significance of iNEIS ${ }^{\mathrm{TM}}$, there is a great possibility that the implementation will succeed in harvesting the full value of the system. This paper provides the stakeholder-provider with useful guidelines, in the form of recommendations, that need to be implemented to ensure improvement in the effectiveness of iNEIS ${ }^{\mathrm{TM}}$.
\end{abstract}

Keywords: education landscape; learning system of COVID-19 pandemic; virtual class; education management information systems; technology acceptance; system effectiveness

\section{Introduction}

The increase in COVID-19 cases is affecting not only the health sector but also the economy, education and other sectors. COVID-19 has indirectly changed the landscape of the country's education system. The government has issued regulations on the education and learning process at every level of education through the digital ecosystem and big data analytics technology. Here, the goal of education system management, especially during a pandemic, is to increase access, efficiency, effectiveness and 
quality through effective systems of monitoring, evaluation, budgeting and planning. This type of management system is called an Integrated National Education Information System (iNEIS ${ }^{\mathrm{TM}}$ ). iNEIS $^{\mathrm{TM}}$ is aimed at enabling this decision-making by providing data and information. Integrated data and information systems are at the core of iNEIS ${ }^{\mathrm{TM}}$ development in their support of educational management functions throughout the education system (Figure 1) [1].

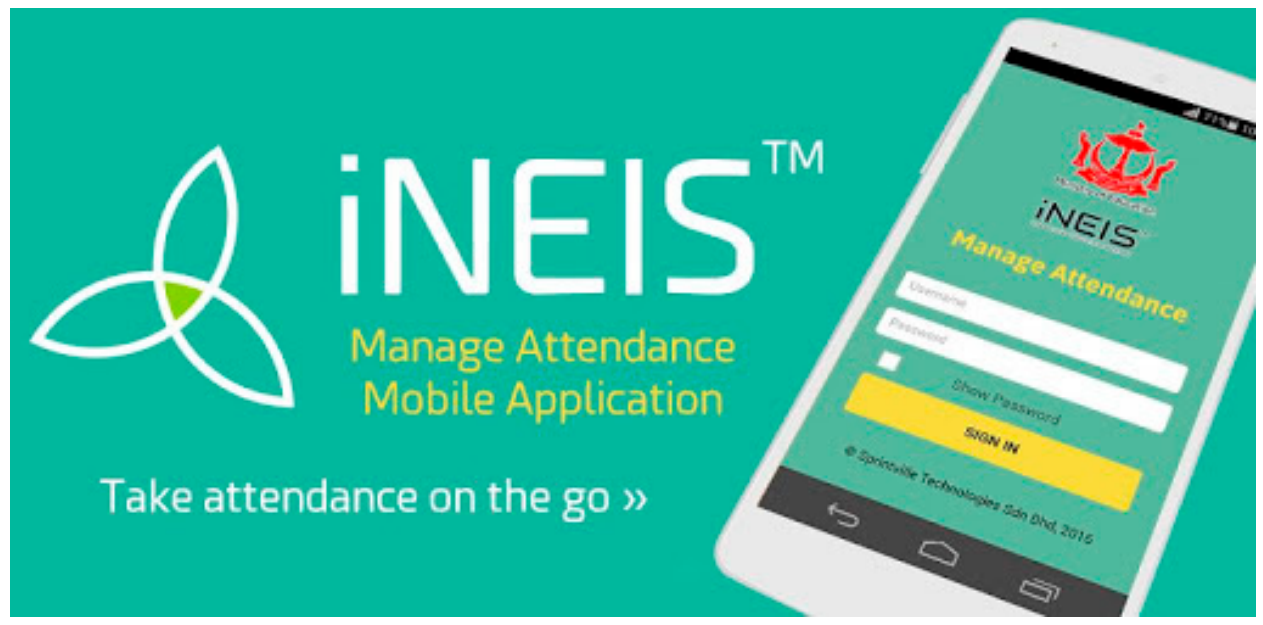

Figure 1. E-Integrated National Education Information System (iNEIS ${ }^{\mathrm{TM}}$ ) user interface.

Looking into the fundamental concepts, the information system (IS) has facilitated the needs and requirements of decision-making not only at the managerial level but also at the operational level. On the other hand, the management information systems (MIS) have changed management discipline in the area of leadership, decision-making, workload, human resources management, communication, responsibility and planning. MIS can convert the collected data from the routine user and machine interactions into valuable information which will be used by the decision-makers to make efficient decisions. Furthermore, it is a collection of related components designed to support operations, management and decision-making through intelligent decision stages based upon the information derived from reliable data that aims at facilitating exchange and information sharing within an organization. Similarly, in the context of education, continuous monitoring and evaluation of the education system by collecting and examining data and information are used in the process of educational decision-making. Several surveys have been conducted in recent years to gather information on the extent to which schools are developing the capacity to integrate MIS into learning, teaching and management processes [2]. Moreover, it was clear that an important feature to be considered was the relationship between data collection and collation to data use. School managers needed different forms of analysis compared to the analysis needed by teachers. A series of studies highlighted important features of computerized school and management systems; their implementation in a range of schools offers the widest view of ICT (Information and Communication Technology) from the perspective of MIS [1,3-7].

However, the aim of this study was to reveal the effectiveness of the newly implemented integrated iNEIS $^{\mathrm{TM}}$ and its implications for educational management that may be applied during the COVID-19 pandemic, especially to reveal and explain the benefits and challenges that hinder the effective implementation of iNEIS ${ }^{\mathrm{TM}}$ to its full potential. It specifically examines the benefits of the system and also obstacles that hinder the efficiency and effectiveness of the system. This research implies that when both the stakeholder-provider and end-user understand the significance of iNEIS ${ }^{\mathrm{TM}}$, there is a great possibility that the implementation will succeed in harnessing the full value of the system. The study provides the stakeholder-provider with useful guidelines in the form of recommendations to be implemented to ensure improvement in the effectiveness of iNEIS ${ }^{\mathrm{TM}}$. The paper is structured in the following way. Firstly, a literature review describes Education Management Systems in detail. 
Secondly, the methods are discussed that were used in data collection along with the limitations that had been encountered. Thirdly, the key differences and similarities between uses of the terms are shown and discussed with support from findings in the literature that is related to research in the Integrated National Education Information System (iNEIS ${ }^{\mathrm{TM}}$ ). Finally, the results of the different views are discussed and some recommendations are also given in the concluding section.

\section{Literature Review}

\subsection{The Importance of Education Management Systems}

The need for efficient data processing has been the expectation of most educational institutions, including schools. MIS are seen to have the potential to make significant contributions to teaching, learning and administration in schools. By providing reliable and accurate data, it is anticipated that the deployment of MIS in educational management will play an important role in the decentralization process by helping to ensure that the education provision becomes more efficient and responsive to users. MIS are being used by schools to support a range of administrative activities, including attendance monitoring, assessment records, reporting financial management and resource and staff allocation. These systems are distinct from other information systems in that they are designed to be used to analyze and facilitate strategic and operational activities in the organization [8]. The use of computers and technologies in educational institutes was mainly to store student and personal data [9]. However, Visscher [6] believes that MIS can provide administrators and teachers with the information required for informed planning, policy making and evaluation. It is claimed that MIS have changed school management in the areas of leadership, decision-making, workload, human resources management, communication, responsibility and planning. These systems can assist the school head in determining the aims of the school, formulating strategic plans, distributing resources and evaluating staff performance as well as organizational success [10-13].

Zain et al. [14] investigated the impact of ICT on management practices in smart schools in Malaysia. Their analysis revealed some positive changes including the enrichment of ICT culture in schools, better accessibility to information, more efficient administration and higher utilization of school resources. The challenges encountered by the participants' schools were time constraints, higher administrative costs, negative acceptance-support from untrained staff, abuse of the ICT facilities and problems related to the imposed rigid procedural requirements. A reduction in workload, beneficial impact on time management and improvement in the quality of reports have been highlighted as major impacts of MIS on school administration and management. Some studies show that as staff in schools have acquired and developed ICT skills and confidence in using the technologies, they have experienced a reduction in some aspects of their workload. ICT use was valued by senior management in developing school systems for administration and easing management tasks [15-17]. The use of technologies has made administrative work easier with regard to accounts, attendance data and the sharing of confidential information [18]. In other words, school management information systems increase effectiveness and efficiency by saving time and facilitating the development of alternative solutions for sophisticated problems $[19,20]$.

Here, INEIS ${ }^{\mathrm{TM}}$ presents new concepts and continued improvements for the academic sectors. The purpose of INEIS ${ }^{\mathrm{TM}}$ is to streamline and transform the Ministry of Education business processes to support its current needs to implement, monitor and measure the National Education Scheme (SPN 21) [21-23] (see Appendix A for iNEIS ${ }^{\mathrm{TM}}$ details and descriptions). Basically, iNEIS ${ }^{\mathrm{TM}}$ was designed to ease the administrative work of teachers. The system would allow teachers to focus on teaching and schools to update the details of teachers' workloads directly and properly; for attendance, curriculum, results and school fees, it is just a matter of one click, and the data are submitted to their destination automatically. The introduction of iNEIS $^{\mathrm{TM}}$ has evidently reduced the time needed to take attendance for teachers. This aspect was one of the methods adopted by the Ministry of Education to lessen the burden of teachers who must carry out extra administrative work in addition to teaching. 
More importantly, a ninety-five percent attendance rate across government primary and secondary schools has been recorded since the implementation of the online attendance monitoring system.

\subsection{Effectiveness of Educational MIS}

iNEIS $^{\text {TM }}$ development is a government initiative as an E-Government implementation that uses ICT to offer citizens and businesses the opportunity to interact and conduct business with government by using different electronic and social media such as email, internet, Twitter, Instagram and Facebook [24-26]. From a technical standpoint, E-Government initiatives usually involve several types of electronic and information systems, including database, networking, discussion support, multimedia, automation, tracking and tracing and personal identification technologies [27] (see Appendix B for E-Government Brunei descriptions). The challenges of E-Government can be translated into the perspective of user's acceptance. User involvement research focuses on two outcome variables: system quality and system acceptance. Underlying these are the more complex issues of cognitive and motivational factors which give rise to improved quality or improved acceptance. Drawing on empirical evidence from qualitative studies [28,29], some have claimed that user participation is essential to the success of systems. User participation is advocated when acceptance is critical, or when information required to design the system can only be obtained from users [12]. ICT adoption and diffusion has been studied in great detail by researchers in the information systems area. ICT acceptance in education remains a central concern of information systems research and practice. Although ICT is playing an increasingly important role in contemporary education, resistance to ICT remains significant in the education sector [30-34].

It is important to note that in addressing the effectiveness of educational management systems, the Technology Acceptance Model (TAM) has been widely applied and used for explaining ICT users' intentions. TAM was originally introduced and studied as a means of understanding how users adopt and use new technology by evaluating the factors that influence the decision to accept a new technology [15]. It is based on the belief "that perceived ease of use and usefulness can predict attitudes toward technology" [16]. The perceived usefulness of a technology and ease of use of a technology combine to create an attitude about the technology, influencing the decision to adopt the technology shaped by external factors unique to the situation, while the behavioral decisions ultimately dictate whether and how a technology is used [35,36].

The theoretical grounding for TAM is the Theory of Reasoned Action (TRA) [37]. The TRA is based on the concept that beliefs influence attitudes, which lead to intentions, which generate the behavior of the systems and users. It specifies the causal relationships between system design features, perceived usefulness, perceived ease of use, attitude toward using and actual usage behavior [38]. The basic premise of this model is that the more accepting users are of new systems, the more they are willing to make changes in their practices and use their time and effort to actually start using the system [39]. The lack of user involvement is one reason for project failure [40]. When TAM is applied to explain the adoption of iNEIS ${ }^{\mathrm{TM}}$, this can be achieved through users' adoption of usability and operability. It follows the tradition of the belief-attitude-intention-behavior relation. According to the logical connection argument, intentions cannot predict behavior as this is linked "analytically" where the causal relationships between these cannot be tested empirically and cannot be subjected to falsification. In view of this paper, instead of asking whether the TAM model is verifiable or falsifiable in relation to iNEIS ${ }^{\mathrm{TM}}$, the more important question to ask is whether the related studies are able to discover new knowledge, develop new exploratory techniques and predict possible outcomes [41,42].

\subsection{Big Data Technologies as Enablers of Digital Education}

Today, in this modernized world, data are generated everywhere: social networks, email, chatting, documents, photos, online purchases, online banking as well as online education. Most of these data are stored in the data warehouse, which is also referred to as a centralized database. The analysis and processing of these huge and complex data are beyond the capabilities of traditional methods. Big data 
are very important as they help in the analysis of decision-making processes within an organization. However, there are three stages to unlocking big data in any organization. Firstly, collection is the first step that should be taken to unlock the value of big data. This involves identifying data that can reveal valuable and useful information. Next is the analysis: once the data are proven to be useful, they should be analyzed in order to obtain actionable information that can be used. However, this is a very complex process, due to the growing diversity of data and the challenges of analyzing these diverse datasets-this is where the complexity of big data lies. Lastly, visualization and application is the last stage of data analysis, where data are made available to users which are understandable and interpretable for further processes such as decision-making [43,44].

The rise of big data, which is a knowledge system, is already changing the objectives of knowledge and social theory in many different fields while also having the potential to transform management decision-making theory $[34,45]$. There have been various attempts to utilize big data in education made around the world. For instance, in places like the USA, there are many schools that are making decisions by utilizing students' individual education data to help them to improve their academic achievement. Big data can influence higher education practice through enhancing students' experiences in order to improve the academic programming, to ensure more effective decision-making and strategic responses to changing global trends. Big data are first stored in the form of large databases and then undergo data processing. In big data processing, there are actually four requirements in total. The first requirement for big data processing is fast data loading, and the second is fast query processing. The third requirement is highly efficient utilization of storage space, and the fourth is successful adaptation to highly dynamic workload patterns. After processing, the next step is big data analytics. Big data are important because they are able to provide information and knowledge of value, which enables one to make a better decision.

The most important technology in utilizing big data is the data mining technique. This technique is used to extract meaningful information from the vast amount of data in the field of education. This meaningful information can be very useful in providing individual learning experiences for the students given the fact that it can create customized learning methods to cater for individuals. For example, analyzing student logs using the mining technique can help lecturers to obtain valuable insights from the data analysis to help them understand the behavior of different students better, and with this, they can create customized education services that are suitable for every single student. It is also important to constantly keep track of the progress of each student as these real-time data can be analyzed further to enable future improvements [46].

Adaptive analytics help to assess a student's level and attention to a particular subject. For example, they will provide students with directed learning to enhance the results of the study by providing the necessary skills and information to help their understanding of a particular subject. On the other hand, social network analytics help to reflect the human relationship-for example, when a student interacts with the learning management system, emails and discussions take place, where information is exchanged regarding their subjects. Discourse analytics analyze contents, comments or thinking in the text of students, which is particularly useful to measure the quality of online education. Text mining is part of discourse analytics. For example, this might involve analyzing online text to determine the degree of interaction between students and measuring the lessons to see the progress of students. However, big data are starting to grow exponentially, especially in the field of education. Governments are beginning to see the potential of big data for education as they have seen what they can do in the area of education [47]. They can be utilized to help evaluate the performance of both schools and teachers, support competitiveness and also improve efficiency. In higher education, there has also been an increase in the usage of data mining and predictive analytics to predict student behavior and classify it, such as to determine those who are likely to drop out from school and how many students are unlikely to achieve passing grades [48-53].

Analytics refers to use of data mining techniques to develop decision-making processes that convert data into actionable insights, uncover patterns, alert and respond to issues and plan for 
the future. Big data analytics can also be useful in terms of monitoring students' performance and supporting decision-making and students' admission processing, which will help to shorten these lengthy processes. Moreover, colleges can benefit from the use of big data and learning analytics by shifting from the traditional methods of delivering instructions face-to-face and devising time-sensitive learning analytics applications-for example, by utilizing a learning management system (LMS), which is commonly used in universities to provide easy access to lecture slides, facilitate discussions in discussion boards, organize quizzes online and monitor students' activity [34]. In the field of higher education, where big data have been implemented, higher education institutions are beginning to reap the tangible and intangible benefits that come from it. The reason for this is that higher education institutions are now making critical and strategic decisions with the support of big data as they provide valuable insights gained from data collection and analysis. With data mining tools, universities have been devoting great effort to compiling and tracking students' data-more so than ever before. Examples include data relating to students entering and leaving university, student performance details, learning progress and their probability of success. The use of big data in the field of education will lead to better quality education and more experienced students and teachers as compared to the past.

\section{Methodology}

The triangulation research methodology was used in this study, which was a combination of both qualitative research and quantitative research [53,54]. While the qualitative research aimed to gather an in-depth understanding of the impact of the iNEIS ${ }^{\mathrm{TM}}$ system, both from the developer's and from the end-users' point of view, the quantitative aspects explored the perceptions towards iNEIS ${ }^{\mathrm{TM}}$. There were 300 respondents who participated in the online survey questionnaire and it received quite overwhelming responses. Most responses were received through social media, i.e., Whatsapp and Facebook. The sample size is significant based on the confidence level of $95 \%$ and $5 \%$ margin of error for a population of around 8000 teachers of public schools.

Purposive sampling was used to focus on iNEIS ${ }^{\mathrm{TM}}$ users and implementers, who represent a particular population that is of interest, which was appropriate to enable us to address the aims of this paper. The questionnaire survey mainly used closed-ended questions and one open-ended question for respondents to answer. In addition, a semi-structured face-to-face interview was adopted to enable us to gain in-depth information about iNEIS ${ }^{\mathrm{TM}}$ usage experience. The survey responses were analyzed using descriptive statistics and were transformed into graphical charts, whereas the interviews were recorded in audio form, transcribed and transformed into written documents for thematic analysis purposes. The research applied several ethical considerations to maintain the validity and reliability of the data collected. All information and data from respondents were treated as strictly private and confidential; anonymity was maintained and consent obtained prior to survey and interviews.

\section{Findings}

The purpose of conducting the quantitative survey was to explore further the perceptions, opinions, issues and implementation of iNEIS ${ }^{\mathrm{TM}}$. From the findings, it is apparent that teachers from all over the nation participated in the survey and the largest group comprised teachers from the Brunei-Muara District $71 \%$, Tutong $18.7 \%$, Belait $8.7 \%$ and Temburong in the remaining $1.6 \%$ (Figure 2). 


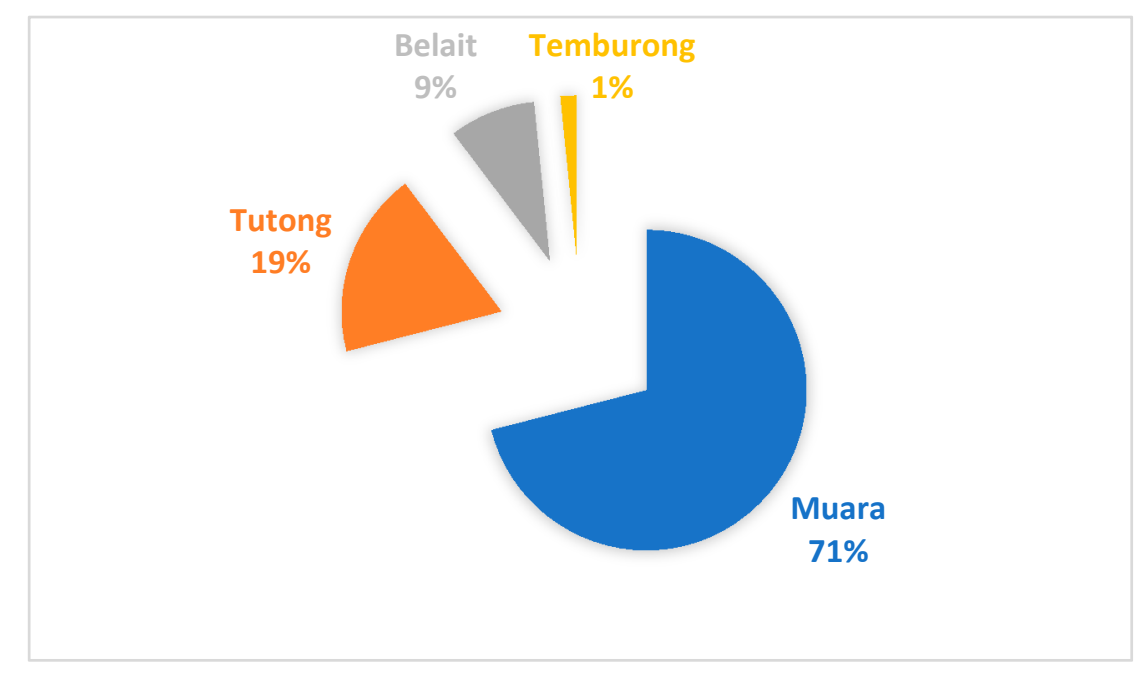

Figure 2. Respondents profile.

\subsection{User Experiences}

The findings show that $16 \%$ of the respondents were teachers who had been in service for 16 years and above. This question was included in the survey to determine the relationship between the age factor and the behavior of older generations to accept change. As was highlighted in the survey, this group was the most resistant to change. Referring to the interview responses, the older/senior teachers in schools were the most reluctant people to use the new system. They showed no interest in learning how to use iNEIS ${ }^{\mathrm{TM}}$ and required the junior teachers to help them. The user respondents of iNEIS $^{\mathrm{TM}}$ included teachers, education officers and also school leaders. "Education officers" were degree holders whilst "teachers" in this context were teachers who were diploma holders. School leaders were headmasters/headmistresses/principals of schools. More than half of the respondents were teachers from primary schools. There was no difference in the allocation of responsibility in the use of iNEIS ${ }^{\mathrm{TM}}$ between primary and secondary schools. The significance of this question was to collect the different opinions and points of view of teachers from both primary and secondary schools. Although the responsibilities of teachers in all schools were more or less similar, the culture and working environment varied.

\subsection{Workload Issues}

The implementation of the new system, iNEIS ${ }^{\mathrm{TM}}$, was seen as an additional burden to teachers. From the literature, Sandy Britain, a specialist at Education Enterprise Architecture (EEA), said that the system would allow teachers to focus on teaching, and schools could update details through the system and would not need to search for information through spreadsheets. From the responses to our survey, this is not the case. The goal of iNEIS ${ }^{\mathrm{TM}}$ was to minimize teachers' overall workload, but we found otherwise. In total, $93.7 \%$ of the respondents, which was around 281 out of 300 teachers, claimed that the system did not help them at all. Although almost all the teachers underwent training before they started to use iNEIS ${ }^{\mathrm{TM}}$, only $21.3 \%$ (around 64 out of 300) of them fully understood the whole function of the system. There were even users who had no knowledge about the system at all. The neutral responses were assumed to have 50-50 knowledge. Some teachers stated in the survey that the reason some users were less committed to accepting iNEIS ${ }^{\mathrm{TM}}$ might have been that there was no prototyping, and during training, there was no clear justification of the benefits of the new system.

\subsection{Problem of $\mathrm{NNEIS}{ }^{T M}$}

More than half of the participants $(61 \%)$ agreed that the system (iNEIS ${ }^{\mathrm{TM}}$ ) was the main cause of the problem and internet connection was second (23\%). This was mainly due to the system and 
internet connection being unstable most of the time. Moreover, since the implementation of the system, teachers had to fulfil "double jobs". First, they were required to enter and update data in the system, and at the same time, they had to produce hard copy reports. This might also be due to the lack of users' involvement during system development. The process of involving users in the system development is critical to the success of any development project. User involvement has played a prominent role in the success of system development efforts. Referring to the recent news in the mass media, UNN (Unified National Networks) is working on improving the internet connection and has announced that faster internet connection will be provided throughout the national coverage. On the other hand, according to the teachers during the interview, they had only undergone one initial training session before the implementation of iNEIS $^{\mathrm{TM}}$. The majority, $70 \%$, agreed that the training was inadequate. When the system was launched and first started to be used in schools, teachers were still uncertain about the whole system. The system was still ambiguous to them and they had to learn for themselves the functions and processes embedded in the system despite being unsure about it.

\subsection{With or without iNEIS ${ }^{T M}$ ?}

This question intended to determine the users' perceptions of iNEIS ${ }^{\mathrm{TM}}$ as a tool to make work easier. Around $82 \%$ of the respondents still preferred to carry out their job using the traditional way, without using the newly implemented IS. Despite the "struggle" that most users faced in using the system, $10 \%$ of the respondents accepted that iNEIS ${ }^{\mathrm{TM}}$ made it easier to complete their job. Lack of user involvement traditionally has been the major reason for project failure. Conversely, the main contributor to project success has been user involvement. However, among the most common comments and recommendations that were made by the respondents were the following:

i. The system needed lot of improvement in order to be an effective system.

ii. The main listed reason for this was the unstable internet connection and also the instability of the system itself. It was intended for the new system to replace the manual system, but now, with iNEIS ${ }^{\mathrm{TM}}$, both are needed.

iii. The system had a complicated interface, was not user-friendly, had too many technical terms and had too many components that tended to confuse users.

iv. Teachers should have been able to focus on teaching rather than spend a great deal of time on iNEIS $^{\mathrm{TM}}$ attending to the errors and complications of the system.

v. There was an ack of support from the iNEIS ${ }^{\mathrm{TM}}$ team and helpdesk.

vi. The initial training was inadequate for teachers to master the system and to use it effectively.

vii. Internet connection should be improved for better and stable connection of the system.

viii. iNEIS $^{\mathrm{TM}}$ placed a greater burden on teachers in terms of both academic and non-academic tasks.

Even though most of the comments criticized the inefficiency of the system, a significant number of respondents did find iNEIS ${ }^{\mathrm{TM}}$ to be a good system. A few accepted the system as a good one once they were familiar with it. Some suggested that more training, and awareness of the benefits of the system, would be beneficial, and more support from the iNEIS ${ }^{\mathrm{TM}}$ team was required. Some respondents also requested for the interface of iNEIS $^{\mathrm{TM}}$ to be redesigned to be less complicated, more user-friendly and simpler. In essence, the purpose of iNEIS ${ }^{\mathrm{TM}}$ is only to provide statistical figures. From these, other departments can generate reports and begin to analyze the data. It was discovered from the teacher's perspective that a number of them prefer to use the traditional method and argued that the system was acceptable if no problems occurred. The findings further showed that there were barriers that made the system ineffective and inefficient. These barriers included the internet connection, the system itself and also the users' attitudes towards change.

\section{Discussion}

Consolidation of our findings and analysis enabled the iNEIS ${ }^{\mathrm{TM}}$ framework to be developed as shown in Figure 3. The findings reveal that the responses provided by the teachers during the 
interview were similar to the comments that were written by other respondents who participated in the questionnaire. This created difficulty for the users (especially teachers) as it created double the amount of work for them, which might have affected their time for teaching. However, the respondents also believed that the system did have potential to be good and beneficial if only adequate necessity for its development was provided. Otherwise, the system would not work effectively and would increase the workload for the teachers as a result. This is in line with the authors of [6,7], who believe that MIS can provide administrators and teachers with the information required for informed planning, policy making, evaluation and workload reduction. It is claimed that MIS have changed school management in the areas of leadership, decision-making, workload, human resources management, communication, responsibility and planning.

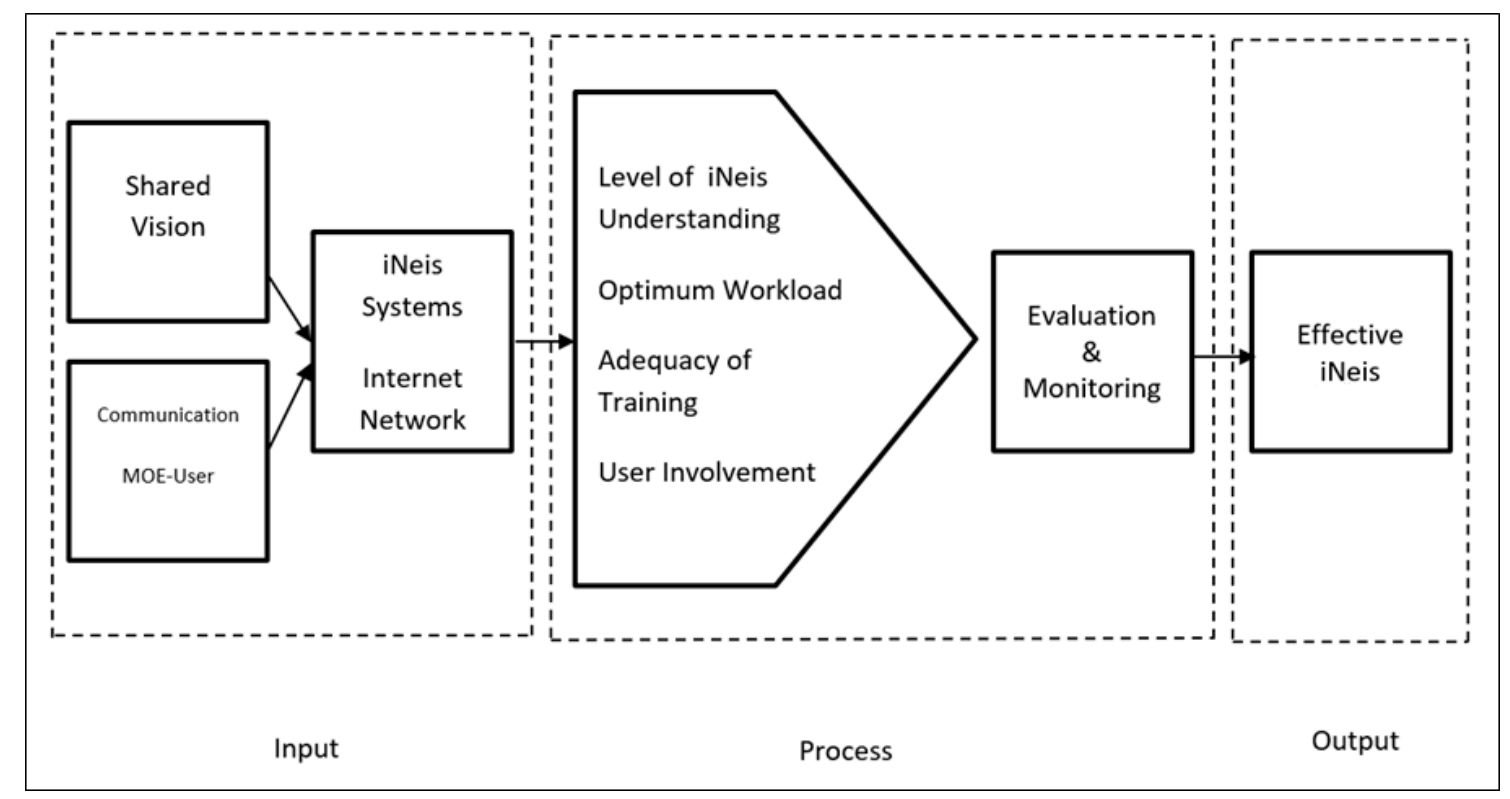

Figure 3. E-iNEIS ${ }^{\mathrm{TM}}$ framework.

Nevertheless, the main issue with the implementation of iNEIS ${ }^{\mathrm{TM}}$ was people's attitudes towards the system as most of them were reluctant to change. Some of the respondents from the questionnaire also mentioned that most users were very "closed-minded" about the implementation of the system. Meanwhile, according to the participants from the interview, some of the users were reluctant because some of them were computer illiterate. Perhaps, if more proper training was carried out, this would help the users to understand better how to use the system and thus more positive feedback from teachers could be obtained. This can be reflected by the theoretical grounding for TAM mentioned in the literature review. As mentioned in the literature review, TAM proposed two important determinants to analyze the factors which caused individuals to accept or reject information technology, namely perceived usefulness and perceived ease of use. The definition of "perceived usefulness" is the degree to which a person believes that using a particular system would enhance his/her job. This determinant may be ambiguous for this particular research. It seems that there were not many participants who considered that the use of the system could enhance his or her job performance, but they rather clarified that the system would usually create more work for them. However, "perceived ease of use" is the degree to which a person believes that using a particular system would be free of effort. This may be true considering that most participants in this research believed that the introduction of iNEIS ${ }^{\text {TM }}$ could minimize any issues when it came to completing certain tasks-they considered that the system could be useful as they believed that by using it, workload could be minimized. However, this did not occur in reality, as many issues arose once it was implemented. For example, the system became unstable and data were not synchronized, which made many users feel reluctant to use the system. 


\section{1. iNEIS ${ }^{T M}$ Big Data and Learning Analytics}

Basically, learning analytics highly emphasize the measurement, collection, analysis and reporting of learners' information with the aim of comprehending and maximizing the learning process as well as the environment in which it takes place. Learning analytics can be referred to as a series of experiments that develop ideas from different fields in terms of process mining, business intelligence, data processing, information retrieval and technology-enhanced learning. It is not solely based on technology or institutional statistics. The core of learning analytics is basically concerned with enhancing individual capabilities that will help individuals to achieve their potential and goals in life. In the big data era, learning analytics carry the possibility to offer educators information and tools that will help them in making decisions and encourage teachers to make full use of the technology through a range of learning concepts (Figure 4). The incorporation of technology for learning purposes gives further information for analysis for supporting an ongoing cycle of continuous improvement. In this case, every educator should be given access to learning analytics tools and given proper training on how to use these tools properly. This can contribute to creating e-proficiency and support the development of targeted and effective learning methods. The strengths of learning analytics include the availability of a huge amount of educational data, the ability to use powerful, preexisting algorithms, the availability of multiple visualizations for staff and students, increasingly precise models for adaptation and customization for learning processes and increasingly valuable insights for learning strategies and behaviors. The opportunities of learning analytics include open-linked data able to enhance compatibility across systems, enhancing self-reflection and self-awareness, enabling the learning process to be carried out through intelligent systems and the feeding of learning analytics outcomes to another system to aid in making decisions. The threats of learning analytics include concerns regarding ethical issues, specifically with regard to privacy issues, over-analysis, insufficient generalizability of the outcomes, higher chances for misclassification of patterns and contradictory findings.

There is a correlation between big data and learning analytics. In numerous points of view within learning analytics, big data are linked to education. Learning analytics has been regarded as an educational application of big data. It basically consists of a branch of statistical analysis that was initially created as a method for businesses to conduct analysis in certain areas such as commercial activities, identifying spending trends and to making predictions regarding consumer behavior. In generic terms, big data expect the use of either information or database systems as the central storage facility as it is suitable for storing vast amounts of data and enabling certain transactions. For instance, the record-keeping framework of undergraduate students has the ability to store the information of undergraduate students in terms of their grades for each course they have taken. For institutional researchers, this kind of information is very useful and it can be used to analyze the performance of students over time. It could be analyzed from one semester to another semester or from one year to another year. In the context of the big data scenario, the information would be obtained for every undergraduate student's transaction in every course, particularly if the course has been conveyed electronically online. This means that every undergraduate student's data, basically on their course evaluation, discussion board section, blog section and any activity, could be recorded and this can produce a large number of transactions for each of undergraduate student per course. Moreover, this information would be gathered on the basis of real time or close to real time every time it is executed, and after this, it will be examined further to recommend the course of action that needs to be taken. The application of learning analytics has been growing rapidly in educational institutions in which the learning process is being carried out online and in hybrid settings. It has become a more standardized type of learning process for educational institutions. A specific kind of web tracking tool has been widely used in educational institutions in order to record student behaviors on online courses. The tracking tools not only record basic variables like how much time students spend on a topic but also more nuanced information that could provide evidence of a student's critical thinking, synthesis and the depth of retention of the information after some time. The data of the specific 
behavior of the student will be added into the student-related information. In this knowledge-based era, the majority of educational activities such as e-learning, tests, quizzes and other activities are being carried out online. Nowadays, students and educators are increasingly connected to the internet because a significant amount of educational material is available in digital format. This proves that the availability of data sources on the internet for learning purposes has been expanding. There are several main sources used for learning analytics, such as the virtual learning environment (VLE), student information system (SIS), learning management system (LMS) and library system.

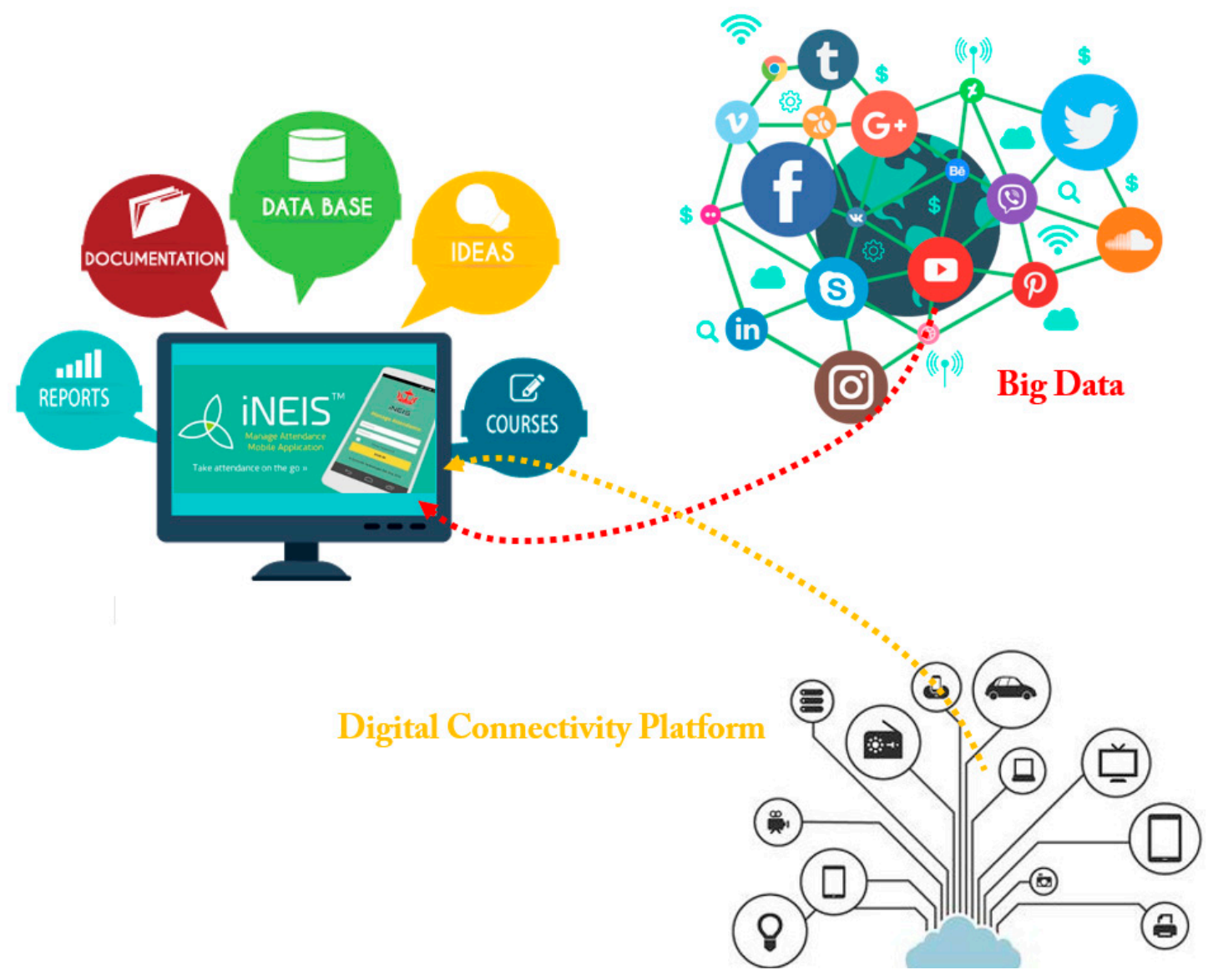

Figure 4. E-iNEIS ${ }^{\mathrm{TM}}$ big data and digital connectivity.

\subsection{Student Information System (SIS)}

The student information system is an important part of the education system, especially in this modern era. It is believed that this system could solve the problems or difficulties with using the traditional approach of gathering relevant information about students through the internet. Moreover, this system is designed to replace the paper-based system of collecting and recording student information, which is time-consuming and difficult to manage. The student information system consists of detailed information about students in terms of their prior qualifications, socio-economic status, ethnic group, module choices and grades achieved to date. From this system, there will be potentially valuable insights that could be used to design a virtual learning environment so that it will be easier to predict student academic performance in education settings (Figure 5). The majority of student information systems are involved in administrative activities such as admissions, enrolment and examinations. It is clear that the use of student information systems can be beneficial for education institutions to record and maintain student information easily, coordinating different levels of student information, providing access to information by students, instructors and parents 24/7 and storing 
biometric system information. Besides the above, the system is user-friendly, ensures efficient services, minimizes the workload of the users and makes it easy to retrieve data.

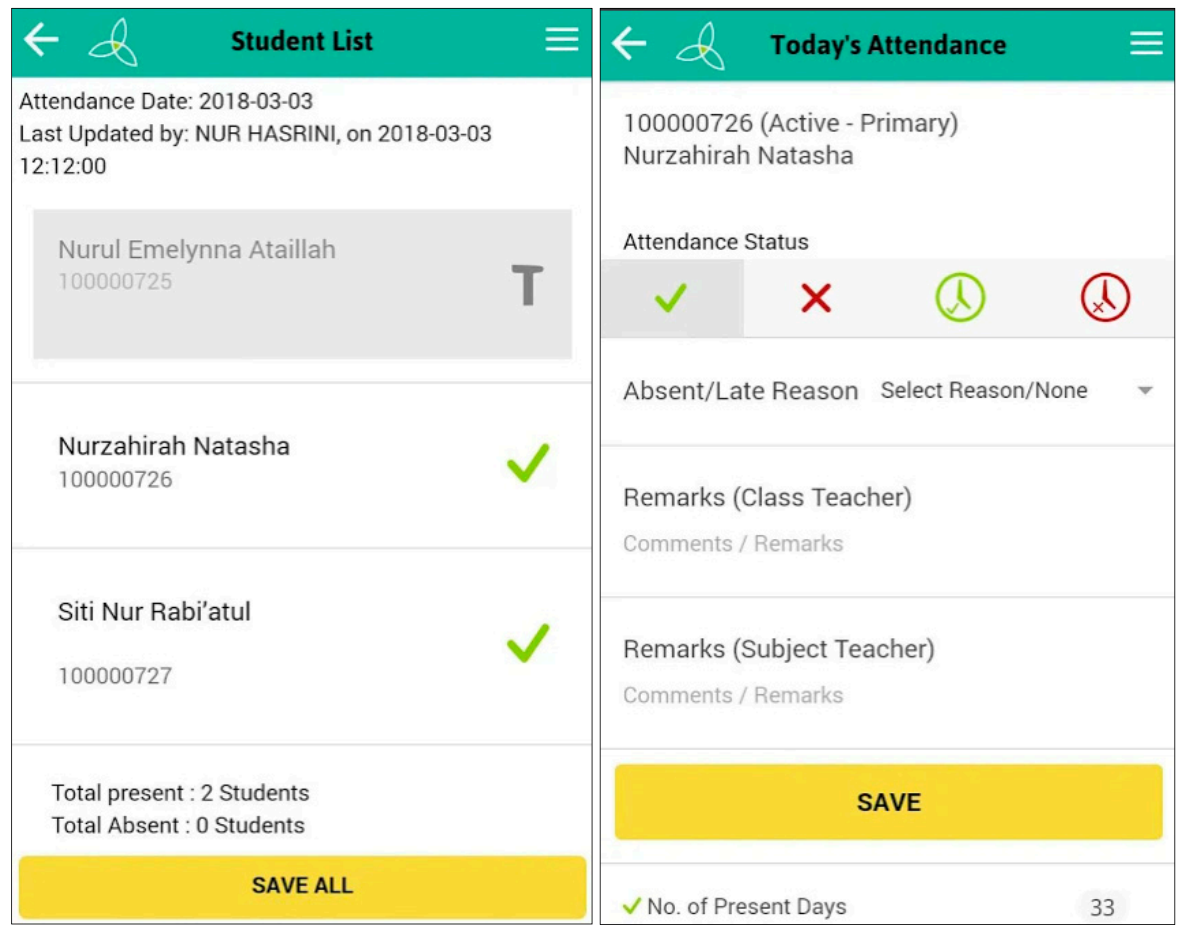

Figure 5. Digital education features.

\subsection{Learning Management System (LMS)}

The learning management system is widely recognized as the framework that manages every aspect of the learning procedure. The use of the framework of the learning management system supports the delivery and management of content and helps in identifying and evaluating individual or organizational learning or training objectives, tracks the progress towards these objectives and gathers and displays the overall information of learning procedure. It also aids in managing course registration, administration, analysis, tracking and reporting. The learning management system is the most common data source for higher educational institutions through an online portal that connects with the lecturers and undergraduate students. The learning process in higher educational institutions is no longer the same as in the primary and secondary school system, which is only a one-way learning process. In higher education systems, the lecturers usually provide lecture notes and extra information for the students to access on their own. This means that in the higher education system, students are encouraged to be exploratory learners throughout their studies. Moreover, throughout the lecture session, the lecturers will share their knowledge on certain topics and students participate by giving their own opinions or thoughts on the related topic during class discussion. Hence, university students need to continuously expand their knowledge by gathering more information. The advantage of using LMS for lecturers is that it is easy to manage a large number of students in the system. This will also save their time as the lecturers can easily identify and monitor their students. For example, the lecturer has three different lecture classes. With LMS, the lecturer can easily determine which students are taking his or her class based on which class the students are registered for. In this case, it will be easier for the lecturer to provide lecture material as well as receive assignments from the student. The drawback of using LMS is that it is difficult to enable active discussion with all the students-for example, when there are hundreds of students posting messages to a lecturer. It is difficult for the lecturer to reply the students' messages specifically. This can be time-consuming and increase the stress level of the lecturer due to excessive messages. 


\subsection{Library System}

Transforming the library into a cloud-based shared system can actually contribute to the success of learning analytics. A vast amount of data could be generated through the library system. Basically, the library system has the ability to record student information, especially when students borrow books from the library or when students access the library system to read electronic journals. This kind of information is very useful for analytics to study the number of expected students visiting the library and student behavior. There are a number of initiatives to enhance the library system in order to provide a future generation of learning tools. One of the initiatives is due to the fact that many educational institutions are looking for distinct collections of sources for teaching purposes. This is where the library system plays an important role as the system consists of diverse academic sources, including thesis papers, past year papers, presentation slides, articles, journals, reports and other sources. Moreover, the source of information used for virtual learning environments and learning management systems usually comes from the library system. The advantage of using a library system is that it is very easy to use. The students or lecturers can simply search for books through the system, without the hassle of going to the library to look for books manually. Not only this, but the system can be accessed $24 \mathrm{~h}$ a day and this makes it convenient for both students and teachers as they can access library sources at any time. Moreover, digital copies of the books, journals, thesis and other academic sources are available. Students and teachers can benefit from this as they do not have to carry heavy books from one place to another. The drawback of using a library system is that when there is no internet connection, the system cannot be accessed.

\subsection{The Challenges of Learning Analytics}

Learning analytics is said to offer greater opportunities in providing the best learning experience for students, especially in this big data era. However, there are a few challenges that need to be taken into account, especially the ethical issues that are likely to occur. One of the ethical issues of learning analytics that can be raised is mislabeling students based on incomplete or incorrect information or incorrect calculation. This factor needs to be considered because the ways in which learners behave either in classrooms or through the internet depend on the level of complexity of personal, emotional, social and economic factors that cannot be directly observable from their behavior alone. In this case, learning analytics may have lessened the effectiveness or limited the learners' choices of access to specific materials or resources. For instance, the adoption of learning analytics could be useful to suggest courses and modules which might improve a particular student's chance of completing their qualification successfully. There will be more likely students taking easy courses with the highest chances of success than those students who are taking courses with a high level of difficulty and more challenging content. In this case, it is essential to include students as active agents and collaborators. Through student-oriented learning analytics and the data being shown to the learners, it will give both lecturers and students the chance for self-reflection and the development of shared understanding. Another ethical issue of learning analytics involves legal issues-specifically, privacy concerns, security and the handling of personal information of the students and the teachers, as this information is needed as part of the educational data for learning analytics. Both teachers and students may raise concerns regarding the security of their personal information and who is likely to access the information about their ability and knowledge $[44,55,56]$. These issues need to be addressed as the students and the teachers definitely require answers regarding the extent to which their personal information is going to be used, because it can be considered unethical if the information is misused and this can actually lead to violating the students' and the teachers' personal information. Apart from this, it should be highlighted how exactly learning analytics can enhance the learning process in educational settings. In this case, it is important to note certain criteria of learning analytics in terms of its reliability, validity, effectiveness and usefulness in generating learning outcomes. Moreover, it is important to consider how prepared are the education institutions for the adoption of learning analytics. This is because not everyone knows how to use big data and learning analytics properly. 
Without proper guidelines on how to effectively use the information, this might affect the performance of the students adversely. It is crucial to make preparations by having expertise on this area and changing the infrastructure in order to ensure effective use of learning analytics in learning processes.

One of the main ways that big data can support higher institutions or universities is through engagement between the students and the institutions. Education institutes have introduced a large number of students' engagement points from big data which can help the students, starting from initial profiling all the way to their graduation from the institution. The student engagement lifecycle considers how the institutes influence and improve the student's engagement and also how it could increase their time in the university through big data-powered applications.

\subsection{Student Acquisition}

Information about past performance and also data of both current and past students can be used to develop profiles that indicate which kinds of students are most likely to be registered in a particular institution. There is a need to employ graphic analysis to review their students' social network to pinpoint their friends or acquaintances which could be the institution's potential new scholars. The universities or institutions could use the students' previous data, such as their high school results and performance and also some other tests that they completed, such as aptitude tests or surveys about their interest, and correlate these results with the universities' graduates and be used to advise the students regarding which major or curriculum to take. It is also necessary to incorporate outsource data in regard to the future workforce competence and ability requirements and income, which can help the students to make the correct choice to decide which minor or major will be suitable for their future.

\subsection{Student Performance Effectiveness}

The students' current test results are compared to their previous ones and similar students with similar grades are grouped together and monitored. The lecturer's notes and social media data such as tweets, blogs, YouTube and hashtags should be incorporated in order to develop a much more precise profile of the individual's weakness and attitudes. Creating individual tutoring or small group tutoring for those students who are having problems or even advising them to change their major could be recommended to help those students who are having trouble. The appendix section of this report shows an example of the student progress flow analysis.

\subsection{Student Work Groups}

To improve a student's individual performance, the universities can arrange for a leverage cohort analysis which enables the students to work together both inside the class and also outside the lectures, which can help them to improve their individual achievements. This activity then enables the lecturers to identify the group's assignment and the reasons and factors for those assignments and it also allows the lecturers to cancel. These analytics can reorganize the group task depending on outlined design components and also other factors in which the lecturers need to write down their conclusions, which are to be combined with the purpose of the group performance after reorganizing in order to amend the dataset. The appendix section shows an example of the student cohort analysis.

\subsection{Student Retention}

The next application is to incorporate past data and grades, which include their effectiveness and also their group works, which it then connects with respective demographic, social data and also financial in order to grade the possibility attrition and distribute suggestions, which enables the universities to reach a decision regarding whether to keep the student or not. Through distributing and measuring the success of a particular suggestion, it allows the lecturers to come up with their own suggestions, in which it could check for possible outcomes and can be practiced in forthcoming detention interference propositions. 


\subsection{Teacher Effectiveness}

This application section concerns adjusting and measuring the lecturer's achievements. Their achievement can be measured by the number of students, the students' probabilities and their attitude categories, subject matter and also a few other variables which can certify that the lecturers have the best experience for the students and lectures. Refer to Figure 5 for an example of teacher effectiveness analysis.

\subsection{Student Lifetime Value or Booster Effectiveness}

It is necessary to plan in advance with consideration of offering possible levels for both undergraduates and postgraduates. The major influence of targeting, profiling and messaging to improve postgraduate success is determined by understanding the possibilities of achieving new or forthcoming potential of income and prosperity. Individuals who take advantage of these are the initially recognized as forthcoming supporters.

\subsection{Student Advocacy}

Data from the individual's social network or their grades are used to come up with a student advocacy score which can influence the student's acquisition, in which it targets a successful student's peers; retention, by flagging any adjustments which could be made to avoid retention complications; performance effectiveness, by flagging adjustments which could be made to prevent lecture room achievement complications; and lifetime value applications.

\subsection{Bookstore Effectiveness}

The last big data-powered application is the bookstore effectiveness, which involves the use of the retail industry's finest proceedings to upgrade bookstore benefits using analytics-driven applications such as textbook stock optimization and also merchandising effectiveness.

\section{Conclusions and Recommendations}

In conclusion, there were more undesirable impacts to the end-users resulting from the implementation of iNEIS ${ }^{\mathrm{TM}}$. The surveys that were conducted showed that the users are still not ready to accept the organizational change. Management Information Systems have changed school management in the areas of leadership, decision-making, workload, human resources management, communication, responsibility and planning. The intended purpose of the system, to lessen the workload of teachers, was proven to be unfulfilled. Since iNEIS ${ }^{\mathrm{TM}}$ is fairly a new system, it needs more time to be accepted. In comparison to other studies, likewise, the adoption of E-Government websites/services is significantly related to the quality of information systems.

A number of users cannot accept the system as it is seen to be an additional burden. ICT adoption and diffusion has been studied in great detail by researchers in the information system area. However, ICT acceptance in education remains a central concern of information systems research and practice. Although IT is playing an increasingly important role in contemporary education, resistance to IT remains significant in the education sector. Understanding the conditions under which ICT are or are not accepted and used continues to be an important issue. iNEIS $^{\mathrm{TM}}$ is not a failure but there are symptoms showing that the system is not being used effectively. Based on the analysis, this is due to a lack of some factors such as a culture of communication and information sharing.

Resistance to adopting a culture of information use can often be attributed to a lack of shared vision for system development-in this case, iNEIS ${ }^{\mathrm{TM}}$. A shared vision is one that is developed from individuals' visions for iNEIS ${ }^{\mathrm{TM}}$ — what it should be, how it should function, what goals it seeks, how it should be able to improve the education system for the common good. Without a shared vision, units and individuals within the ministry are less likely to feel ownership of the system and are less likely to be proactive in the advancement of iNEIS ${ }^{\mathrm{TM}}$. Although problems appear to be many and 
known to all, an analysis of these problems and the capability of identifying strategies for resolving these problems remains inadequate. System monitoring and evaluation is yet to be institutionalized; research and analysis is yet to be established. However, iNEIS ${ }^{\mathrm{TM}}$ needs a clear vision to see and know what to produce, who the product is designed to support and which departments and units to include. The development of iNEIS ${ }^{\mathrm{TM}}$ involves nurturing a new management culture more than establishing a data and information system. The process of data collection, integration, analysis and dissemination is important, but even more critical is the culture of data sharing, information use and organizational management that leads to the effectiveness of iNEIS ${ }^{\mathrm{TM}}$.

Author Contributions: F.I. and H.S. were the main contributors and lead authors for this research publication. P.K.H. and D.S. remained as contributors and helped to improve the manuscript and search the literature. All authors have read and agreed to the published version of the manuscript.

Funding: This research received no external funding.

Acknowledgments: Many thanks to Mariani Abdul Kadir and Shamsiah Burut for the assistance in data collection. We are indebted to the Ministry of Education of Brunei, who granted access for the research to be conducted.

Conflicts of Interest: The authors declare no conflict of interest.

\section{Appendix A. Description of Brunei Education Management Information Systems (iNEIS ${ }^{\text {TM})}$}

iNEIS $^{\text {TM }}$ stands for Integrated National Education Information System, which has launched live online and is accessible to all schools. The purpose of INEISTM is to streamline and transform the Ministry of Education business processes to support its current needs to implement, monitor and measure the National Education Scheme (SPN 21). The INEIS ${ }^{\mathrm{TM}}$ function is to provide an application and technology platform to cater to the needs of the Ministry of Education of Brunei Darussalam. The rapid growth of student enrolment and significant change in operational processes required to comply with SPN21 have resulted in the need for INEIS ${ }^{\mathrm{TM}}$ by the ministry. INEIS ${ }^{\mathrm{TM}}$ has been designed to provide a platform for harmonized and streamlined business processes and the flexibility to meet future operational processes, business needs and integration needs. With the implementation of INEISTM $^{\mathrm{TM}}$, the ministry aims to significantly improve operational efficiency and productivity and provide better services, value and "holistic education" to students.

There are five objectives of iNEIS ${ }^{\mathrm{TM}}$, which are as follows:

- To track individual student progress in SPN21 outcomes.

- To reduce administrative load on teachers.

- To improve data quality.

- To transform organizations to be more transparent, efficient and accountable.

- To support, measure, optimize and sustain the implementation of SPN21.

The characteristics of iNEIS ${ }^{\mathrm{TM}}$ are described below:

i. Integrated: Business processes in iNEIS ${ }^{\mathrm{TM}}$ are integrated with each other. Student data are maintained in one place and used in-hand with other processes.

ii. Centralized: It is a single system used by Schools and MoE. Data entered at each school are retrievable at MoE, thus reducing manual intensive submissions to MoE.

iii. Accessibility: It is a web-based system and it will be accessible by authorized users anywhere and anytime as long as they have internet access.

iv. Efficient: Eliminate waiting period and reduce manual tasks. Administrative work can be done at a faster pace, hence allowing efficient operations.

iNEIS ${ }^{\mathrm{TM}}$ runs 24 processes in day-to-day school operations, as listed below: 


\begin{tabular}{cc}
\hline Manage Student Recruitment & Manage Clearance \\
Manage Student Admission & Manage School Resources: Scheduling and Timetable \\
Manage Attendance & Manage Curriculum Materials (Hardcopy) \\
Manage Assessment & Manage Student Pass \\
Manage Examinations & Manage Invoice (Billing) \\
Manage Student Progression & Manage Awards \\
School Management & Manage Co-Curricular Activities (CCA) \\
Manage Academic Operation & Manage Collection \\
Manage Transfer Students & Manage Scholarships and Bursaries \\
Manage Withdrawal & Statistics and Reporting \\
Manage Deferment & Manage Teacher and Student Records \\
Manage Student Allowances & Manage Student Discipline \\
\hline
\end{tabular}

Basically, an "Integrated National Education Information System (iNEIS ${ }^{\mathrm{TM}}$ )" was designed by a consultant to ease the administrative work of teachers. The system would allow teachers to focus on teaching and schools could update details through the system and not need to search for information through spreadsheets. The Acting Assistant Director of the ICT Department at the Ministry of Education, Zainal Abidin bin Hj Kepli, said that, in the past, a lot of teachers complained that the load of administrative tasks was hampering their main duty-teaching. He added, "with iNEIS ${ }^{\mathrm{TM}}$, which is used for attendance, curriculum, results, school fees and etc., it is just a matter of one click, and the data will go to its destination automatically". iNEIS ${ }^{\mathrm{TM}}$ is an integrated system which aims to streamline processes and track individual student progress in SPN21 outcomes. iNEIS ${ }^{\mathrm{TM}}$ aims to give a boost towards ensuring the full attendance of students at school and at the same time make the enforcement of the Compulsory Education Act more effective.

Yang Berhormat Pehin Orang Kaya Seri Kerna Dato Seri Setia Dr Awang Haji Abu Bakar bin Haji Apong (the former minister of MOE), during the Ministry of Education discussion session with members of the Legislative Council, said that one of the elements found in iNEIS ${ }^{\mathrm{TM}}$ was direct monitoring of student attendance. According to Yang Berhormat Pehin, through the system, the integrity and quality of students' class attendance data from the start of the year can be prepared promptly and accurately as well as with detailed analysis for the use of all parties of interest. He added that educators can use the system to form statistics and make reports automatically, which will be more beneficial and reduce the time needed to take attendance as well as allow them to devote more attention towards their teaching.

As the iNEIS ${ }^{\mathrm{TM}}$ has begun its full implementation, all primary schools must aim for a 95 percent pupil attendance rate, which the minister of education announced in a meeting with primary school leaders at Sengkurong Sixth Form Centre. The minister went on to say that the new key performance indicator (KPI) will help to measure students' achievements in their school attendance and for school leaders and parents to effectively monitor and support students' learning development.

As reported in the Borneo Bulletin, the introduction of the Integrated National Education Information System (iNEIS ${ }^{\mathrm{TM})}$ has evidently reduced the time needed to take attendance for teachers. This aspect was one of the methods taken by the Ministry of Education to lessen the burden of teachers who must complete extra administrative work in addition to teaching. More importantly, a ninety-five percent attendance rate across government primary and secondary schools has been recorded by the Ministry of Education (MoE) since the implementation of its online attendance monitoring system iNEIS ${ }^{\mathrm{TM}}$.

Apart from the above, the MoE is compiling data on co-curricular activities in schools through an online system to encourage students to take up at least one co-curricular activity throughout their academic years. It is reported that the data are collected through the Integrated National Education Information System. iNEIS ${ }^{\mathrm{TM}}$ was launched to track and monitor students' attendance. The purpose is that the data-driven web application will ensure full participation of students in co-curricular activities. The id iNEIS ${ }^{\mathrm{TM}}$ will allow teachers to streamline the management of co-curricular activities and ensure that students in primary and secondary schools participate in at least one co-curricular 
activity throughout their school years. This is to encourage students to stay active by making physical, mental or spiritual wellbeing a priority by participating in co-curricular activities at school.

Aside from the description of the functions and characteristics above, iNEIS ${ }^{\mathrm{TM}}$ as an Educational Management Information System is also a set of formalized and integrated operational processes, procedures and cooperative agreements by which data and information about schools and schooling, such as teachers, students, learning activities and evaluative outputs, are regularly shared, integrated, analyzed and disseminated for educational decisions used of each level of the educational hierarchy. While the INEIS ${ }^{\mathrm{TM}}$ function is to provide an efficient administrative service for schools and MoE, the role is for teachers to focus more on teaching. iNEIS ${ }^{\mathrm{TM}}$ is designed as a centralized and integrated system which supports processes in schools and $\mathrm{MoE}$ to be more efficient with a high degree of accessibility.

\section{Appendix B. E-Government}

E-Government has the ability to reduce communications and information costs, maximize speed, broaden reach and eradicate distance. It can improve current government services, increase accountability, result in more accurate and efficient delivery services, reduce administrative costs and time spent on repetitive tasks for government employees, facilitate greater transparency in the administration of government and allow greater access to services due to the round the clock availability of the internet.

E-Government activities can be examined in terms of the interactions between sectors of government, business and citizen. Government-to-government $(\mathrm{G} 2 \mathrm{G})$ initiatives facilitate increased efficiency and communication between parts of a government. G2G initiatives can improve transaction speed and consistency while reducing the time that employees must spend on tasks. For businesses, G2B (Government-to-business) interactions can result in increased awareness of opportunities to work with the government and in cost savings and increased efficiency in performing transactions. For governments, G2B interactions offer benefits in reducing costs and increasing efficiency in procurement processes and provide new avenues for selling surplus items.

Though E-Government has clear benefits for businesses and governments themselves, citizens may actually receive the widest array of benefits from E-Government. Government-to-citizen (G2C) initiatives can facilitate involvement and interaction with the government, enhancing the "degree and quality of public participation in government". G2C interactions can allow citizens to be "more informed about government laws, regulations, policies, and services". For the citizen, E-Government can offer a huge range of information and services, including information for research, government forms and services, public policy information, employment and business opportunities, voting information, tax filing, license registration or renewal, payment of fines and submission of comments to government officials. In summary, E-Government helps in achieving greater efficiency in government performance by raising service performance and service delivery, by eliminating inefficient processes and reducing bottlenecks and red tape in the service delivery process as much as possible.

There are a number of E-Government application systems being implemented in Brunei, named e-Darussalam. The e-Darussalam portal is Brunei's official web portal which aims to facilitate government transactions and delivery of services. Three types of E-Government services are as follows:

(a) PSC

The Public Service Commission's (SPA) online recruitment system went live, which aimed to make it easier for the public and the offices to fill government job vacancies online. The objective of the PSC Recruitment Portal was to replace the manual system and to speed up the application process for government jobs. Applicants receive online notification for interview/test and the result.

(b) GEMS

GEMS, which stands for Government Employee Management System, is an interactive, web-based HRM (Human Resource Management) system spearheaded by the Public Service Department of the Prime Minister's Office to effectively manage the HR functions and operations of the entire Brunei Civil Service. 


\section{(c) Bru-HIMS}

Bru-HIMS (Brunei Darussalam Healthcare Information and Management Systems) is a system that integrates the management of patient information in both the medical and health services. The system seeks to replace the manual patient record system which stores comprehensive patient information and medical history to provide a more effective medical service for the population of Brunei. This system aims to pull together a patient's information and medical history under one file. "One Patient, One Record".

(d) e-Hijrah

The implementation of the MOE's new ICT initiative, "e-Hijrah", as they prepare to transform ICT in education is designed to support and accelerate the rate of change and innovation in the education system initiated by SPN21 and to support the achievement of the goals of Wawasan 2035. iNEIS ${ }^{\mathrm{TM}}$ is one of the e-Hijrah Strategic Pathways under i-Services.

\section{References}

1. Susanto, H.; Caesarendra, W.; Glowacz, A.; Leu, F.; Haghi, P.K.; Khusni, U.; Glowacz, A. Managing Cloud Intelligent Systems over Digital Ecosystems: Revealing Emerging App Technology in the Time of the COVID19 Pandemic. Appl. Syst. Innov. 2020, 3, 37. [CrossRef]

2. Demir, K. School Management Information Systems in Primary schools. Online Submiss. 2006, 5, 32-45.

3. Almunawar, M.N.; Anshari, M.; Susanto, H. Crafting strategies for sustainability: How travel agents should react in facing a disintermediation. Oper. Res. 2012, 13, 317-342. [CrossRef]

4. Almunawar, M.N.; Susanto, H.; Anshari, M. A cultural transferability on IT business application: IReservation system. J. Hosp. Tour. Technol. 2013, 4, 155-176. [CrossRef]

5. North, R.; Strain, D.; Abbott, L. Training teachers in computer-based management information systems. J. Comput. Assist. Learn. 2001, 16, 27-40. [CrossRef]

6. Visscher, A.J. Information technology in educational management as an emerging discipline. Int. J. Educ. Res. 1996, 25, 291-296. [CrossRef]

7. Visscher, A.J. A Fundamental Methodology for Designing Management Information Systems for Schools. J. Res. Comput. Educ. 1994, 27, 231-249. [CrossRef]

8. O'Brien, J. Management Information Systems-Managing Information Technology in the Internetworked Enterprise; Irwin McGraw-Hill: Boston, MA, USA, 1999.

9. Carnoy, M. ICT in education: Possibilities and challenges. In Inaugural Lecture of the Universitat Oberta de Catalunya (UOC) 2004-2005 Academic Year; UOC: Barcelona, Spain, 2004.

10. Auramo, J.; Kauremaa, J.; Tanskanen, K. Benefits of IT in supply chain management: An explorative study of progressive companies. Int. J. Phys. Distrib. Logist. Manag. 2005, 35, 82-100. [CrossRef]

11. Gurr, D. How Information and Communication Technology is Changing the Work of Principals. In Proceedings of the International Congress of School Effectiveness and Improvement, Hong Kong, China, 4-8 January 2000. Available online: http://www.ied.edu.hk/cric/ic2000/s9list.htm (accessed on 23 February 2016).

12. Ives, B.; Olson, M.H. User Involvement and MIS Success: A Review of Research. Manag. Sci. 1984, 30, 586-603. [CrossRef]

13. Telem, M. A case of the impact of school administration computerization on the department's head role. J. Res. Comput. Educ. 1999, 31, 385-401.

14. Zain, M.Z.; Atan, H.; Idrus, R.M. The impact of information and communication technology (ICT) on the management practices of Malaysian Smart Schools. Int. J. Educ. Dev. 2004, 24, 201-211. [CrossRef]

15. Gong, M.; Xu, Y.; Yu, Y. An enhanced technology acceptance model for web-based learning. J. Inf. Syst. Educ. 2004, 15, 365-374.

16. Lederer, A.L.; Maupin, D.J.; Sena, M.P.; Zhuang, Y. The technology acceptance model and the World Wide Web. Decis. Support Syst. 2000, 29, 269-282. [CrossRef]

17. Thierauf, R.J. Creative Computer Software for Strategic Thinking and Decision Making; Greenwood Publishing Group Inc.: Westport, CT, USA, 1993. 
18. Granville, S.; Russell, K.; Bell, J. Evaluation of the Masterclass Initiative, Edinburgh, Scottish Executive. 2005. Available online: https://www2.gov.scot/resource/doc/47121/0020691.pdf (accessed on 11 November 2019).

19. Barki, H.; Hartwick, J. Rethinking the Concept of User Involvement. MIS Q. 1989, 13, 53-63. [CrossRef]

20. Zaheer, N.; Trkman, P. An information sharing theory perspective on willingness to share information in supply chains. Int. J. Logist. Manag. 2017, 28, 417-443. [CrossRef]

21. Susanto, H.; Almunawar, M.N.; Leu, F.-Y.; Chen, C.K. Android vs iOS or Others? SMD-OS Security Issues. Int. J. Technol. Diffus. 2016, 7, 1-18. [CrossRef]

22. Susanto, H. Managing the Role of IT and IS for Suppoting Business Process Reengineering. Available online: https://www.researchgate.net/profile/Heru_Susanto/publication/305116268_MANAGING_THE_ROLE_ OF_IT_IS_FOR_SUPPOTING_BUSINESS_PROCESS_REENGINEERING/links/59e565cfaca272390ed64e18/ MANAGING-THE-ROLE-OF-IT-IS-FOR-SUPPOTING-BUSINESS-PROCESS-REENGINEERING.pdf (accessed on 12 October 2020).

23. Susanto, H.; Kang, C.C.; Leu, F.Y. Revealing the Role of ICT for Business Core Redesign. SSRN Electron. J. 2016. [CrossRef]

24. Mutula, S.M. Comparison of sub-Saharan Africa's e-government status with developed and transitional nations. Inf. Manag. Comput. Secur. 2008, 16, 235-250. [CrossRef]

25. Mohammad, H.; Almarabeh, T.; Abu Ali, A. E-government in Jordan. Eur. J. Sci. Res. 2009, 35, $188-197$.

26. Wangpipatwong, S.; Chutimaskul, W.; Papasratorn, B. Factors influencing the adoption of Thai government websites: Information quality and system quality approach. In Proceedings of the 38th Hawaii International Conference on Systems Science-2005, Big Island, HI, USA, 3-6 January 2005.

27. Jaeger, P.T. The endless wire: E-government as global phenomenon. Gov. Inf. Q. 2003, 20, 323-331. [CrossRef]

28. Hirscheim, R.; Klein, H.K. Four Paradigms of Systems Development. Commun. ACM 1989, 32, 1199-1216. [CrossRef]

29. Lawrence, M.; Low, G. Exploring Individual User Satisfaction within User-Led Development. MIS Q. 1993, 17, 195. [CrossRef]

30. Cornell, R.M.; Eining, M.M.; Hu, P.J.-H. The Effects of Process Accountability on Individuals' Use of a Familiar Technology. J. Inf. Syst. 2011, 25, 109-128. [CrossRef]

31. Dasgupta, S.; Granger, M.; McGarry, N. User Acceptance of E-Collaboration Technology: An Extension of the Technology Acceptance Model. Group Decis. Negot. 2002, 11, 87-100. [CrossRef]

32. Grant, K.; Hackney, R.; Edgar, D. Strategic Information Systems Management; Cengage Learning EMEA: Cengage, UK, 2010.

33. Saxena, P.; Stavropoulos, P.; Kechagias, J.D.; Salonitis, K. Sustainability Assessment for Manufacturing Operations. Energies 2020, 13, 2730. [CrossRef]

34. Susanto, H.; Chen, C.K.; Almunawar, M.N. Revealing Big Data Emerging Technology as Enabler of LMS Technologies Transferability. In Studies in Big Data; Springer Science and Business Medi: Berlin/Heidelberg, Germany, 2017; pp. 123-145.

35. Davis, F.D. Perceived usefulness, perceived ease of use, and user acceptance of information technology. MIS Q. 1989, 13, 319-340. [CrossRef]

36. Davis, F.D.; Bagozzi, R.P.; Warshaw, P.R. User acceptance of computer technology: A comparison of two theoretical models. Manag. Sci. 1989, 35, 982-1003. [CrossRef]

37. Fishbein, M.; Ajzen, I. Belief, Attitude, Intention, and Behavior: An Introduction to Theory and Research; Addison-Wesley: Reading, MS, USA, 1975.

38. Davis, F.D. User acceptance of information technology: System characteristics, user perceptions and behavioral impacts. Int. J. Man-Mach. Stud. 1993, 38, 475-487. [CrossRef]

39. Jones, C.M.; McCarthy, R.V.; Halawi, L.; Mujtaba, B. Utilizing the technology acceptance model to assess the employee adoption of information systems security measures. Issues Inf. Syst. 2010, 11, 9-16.

40. Johnson, J.H. Micro Projects Cause Constant Change; The Standish Group International: Boston, MA, USA, 2001.

41. Ibrahim, F.; Salleh, N.M. Embedding Knowledge Management Theory in Learning and Teaching Approach. Int. J. Learn. Dev. 2019, 9, 19-40. [CrossRef]

42. Lucey, T. Management Information Systems; DP Publications: London, UK, 1991.

43. Clarke, S. Information Systems Strategic Management, An Integrated Approach; Routledge: London, UK, 2001.

44. Susanto, H.; Almunawar, M.N. Information Security Management Systems: A Novel Framework and Software as a Tool for Compliance with Information Security Standard; CRC Press: Boca Raton, FL, USA, 2018. 
45. Susanto, H.; Chen, C.K. Information and Communication Emerging Technology: Making Sense of Healthcare Innovation. In Studies in Big Data; Springer Science and Business Media: Berlin/Heidelberg, Germany, 2017; pp. 229-250.

46. Velázquez, F.D.C.; Méndez, G.M. Augmented Reality and Mobile Devices: A Binominal Methodological Resource for Inclusive Education (SDG 4). An Example in Secondary Education. Sustainability 2018, 10, 3446. [CrossRef]

47. Marrero, S. Student Information System for the University of the Cordilleras. A Master Project Study; University of the Cordilleras: Benguet, Philippines, 2007. Available online: http://www.auamii.com/jiir/vol-01/issue-04/ 4pacio.pdf (accessed on 1 March 2016).

48. Almunawar, M.N.; Anshari, M.; Susanto, H.; Chen, C.K.; De Pablos, P.O. How People Choose and Use Their Smartphones. In Management Strategies and Technology Fluidity in the Asian Business Sector; IGI Global: Hershey, PA, USA, 2018; pp. 235-252.

49. Almunawar, M.N.; Anshari, M.; Susanto, H.; Khosrow-Pour, D.M. Adopting Open Source Software in Smartphone Manufacturers' Open Innovation Strategy. In Encyclopedia of Information Science and Technology, 4th ed.; IGI Global: Hershey, PA, USA, 2018; pp. 7369-7381.

50. Almunawar, M.N.; Susanto, H.; Anshari, M. The Impact of Open Source Software on Smartphones Industry. In Encyclopedia of Information Science and Technology, 3rd ed.; IGI Global: Hershey, PA, USA, 2015; pp. 5767-5776.

51. Leu, F.-Y.; Ko, C.-Y.; Lin, Y.-C.; Susanto, H.; Yu, H.-C. Fall Detection and Motion Classification by Using Decision Tree on Mobile Phone. In Smart Sensors Networks; Elsevier BV: Amsterdam, The Netherlands, 2017; pp. 205-237.

52. Leu, F.-Y.; Liu, C.-Y.; Liu, J.-C.; Jiang, F.-C.; Susanto, H. S-PMIPv6: An intra-LMA model for IPv6 mobility. J. Netw. Comput. Appl. 2015, 58, 180-191. [CrossRef]

53. Saunders, M.; Lewis, P.; Thornhill, A. Research Methods for Business Students, 5th ed.; Financial Times: Harlow, UK; Prentice Hall: Harlow, UK, 2009.

54. Creswell, J.W. Educational Research: Planning, Condcuting and Evaluating Quantitative and Qualitative Research, 4th ed.; Pearson: Boston, MA, USA, 2012.

55. Susanto, H.; Almunawar, M.N. Security and Privacy Issues in Cloud-Based E-Government. In Advances in Electronic Government, Digital Divide, and Regional Development; IGI Global: Hershey, PA, USA, 2016; pp. 292-321.

56. Susanto, H.; Almunawar, M.N. Managing Compliance with an Information Security Management Standard. In Encyclopedia of Information Science and Technology, 3rd ed.; IGI Global: Hershey, PA, USA, 2015; pp. 1452-1463.

Publisher's Note: MDPI stays neutral with regard to jurisdictional claims in published maps and institutional affiliations.

(C) 2020 by the authors. Licensee MDPI, Basel, Switzerland. This article is an open access article distributed under the terms and conditions of the Creative Commons Attribution (CC BY) license (http://creativecommons.org/licenses/by/4.0/). 